\title{
Commercial Sexual Exploitation of Children and Young People in the UK
}

- a review

Authors:

Name of Institution:

Correspondence:

Keywords:
Elaine Chase and June Statham

Thomas Coram Research Unit Institute of Education, University of London 27/28 Woburn Square London WC1H OAA

Elaine Chase, as above.

e.chase@ioe.ac.uk

02076126935

Children, prostitution, trafficking, pornography

This is a preprint of an article published in Child Abuse Review 14: 4: 4-25 (2005) See: http://www3.interscience.wiley.com/cgi-bin/jhome/5060

\begin{abstract}
This paper reviews recent information and data relevant to the commercial sexual exploitation of children and young people in the UK. Three main aspects of exploitation are addressed: abuse through prostitution; abuse through pornography; and the trafficking of children and young people to and through the UK for the purposes of commercial sexual exploitation. Most published research in this area relates to young people exploited through prostitution. The review explores the range of vulnerability factors, the processes used to engage young people in prostitution, and the types of support strategies for those being exploited. Rather less information is currently available on the scale of child pornography, or the links between the use of pornography and other forms of sexual abuse. The Internet as a modern technology for proliferating child pornography is discussed, alongside its role in providing opportunities for paedophiles to access and 'groom' children for sexual purposes. Finally, the review provides a summary of research on trafficking of children to and through the UK for the purposes of commercial sexual exploitation, and demonstrates the limited knowledge about this topic.
\end{abstract}




\section{Introduction}

In recent years, there has been an increasing awareness of the extent and scale of abuse of children and young people through sexual exploitation, both internationally and in the UK. Much of this awareness can be attributed to the work of key local and international voluntary and non-governmental organisations that have lobbied for recognition of the problem and have led the way in conducting relevant research.

The Commercial Sexual Exploitation (CSE) of children and young people within the UK falls into three key distinct, although not exclusive, areas: abuse through prostitution; abuse through pornography; and the trafficking of children and young people to and through the UK for the purposes of commercial sexual exploitation. Children and young people are also known to be used in other areas of the sex industry such as stripping and phone sex although there appears to be little written and known about these areas of work.

\section{Current policy context}

Within the UK, the Children Act (1989) provides the legal framework for the care and protection of all children (including those temporarily in the country). Area Child Protection Committees (ACPCs), soon to be replaced by Local Safeguarding Children Boards under proposals in the Green Paper Every Child Matters (HM Treasury, 2003), are responsible for developing and agreeing local policies and procedures for interagency work to protect children.

Working Together to Safeguard Children (Department of Health et al., 1999) and the supplementary guidance, Safeguarding Children Involved in Prostitution (Department of Health et al., 2000) recognise the need to protect children from organised abuse, child pornography, the Internet, and prostitution, and provided relevant protocols for an inter-agency approach towards recognising and responding to the sexual exploitation of children and young people. The National Plan for Safeguarding Children from Commercial Sexual Exploitation (Department of Health and Home Office, 2001), updated in 2003, provides the national strategy for safeguarding children from commercial sexual exploitation for 2003-05.

In May 2004, the Sexual Offences Act replaced the 1956 Act, and represented a major overhaul of the legislation. The Act defines a child as someone below the age of 18 years, and not 16 years as in the 1956 Sexual Offences Act. A new offence of 'commercial exploitation of a child' implies legal protection for children up to 18 from exploitation through prostitution and pornography. It includes a number of new offences with strict penalties, and for the first time differentiates between children and young people, with harsher penalties of up to life imprisonment incurred for those exploiting children under the age of 13 years. New clauses have the potential to award further protection from CSE including Clause 17, introducing the offence of sexual 'grooming' of children; and Clause 110, introducing a new 'Risk of Sexual Harm Order'.

\section{Scope and purpose of the review}

The negative impact on young people of abuse through prostitution, and the complexities surrounding the contexts in which this takes place in the UK, have now been well documented (Palmer, 2001; Barnardos, 2002; Pearce, 2003). However, there is still little hard data on the scale of the problem (Swann \& Balding, 2001; Pearce, 2000). Less has been written about other forms of sexual exploitation of 
children such as child pornography and related activities, or the trafficking of children for the purposes of sexual exploitation.

Using published and unpublished literature and relevant statistical data, this paper provides an overview of the types of commercial sexual exploitation and their scale; the characteristics of those affected and the mechanisms employed to exploit children and young people in the UK. It explores the interface between different forms of exploitation (such as pornography or trafficking and exploitation through prostitution) and the personal impact that such exploitation has on the lives of children and young people. Finally, it discusses the types of approaches that offer protection and support to children and young people involved in prostitution, and considers evidence for the effectiveness of existing preventative mechanisms.

\section{Methodology}

Information was gathered in autumn 2003 from literature and Internet searches and from personal contact with UK specialists in this area of work. All members of an existing forum of experts with responsibility for guiding the National Plan on Safeguarding Children were contacted to identify both key relevant literature (including unpublished or 'grey literature) and on-going research in this field. Next, searches were carried out using relevant databases such as Child Data Abstracts and the electronic library for social care (eLSC), as well as Internet search engines. Key search terms included 'sexual exploitation', 'sexual abuse', 'prostitution', 'pornography' and 'trafficking', combined with 'child' or 'children'. A snowballing approach was adopted, following up references from the most relevant articles. Finally, key websites of all organisations and charities known to work with children who are sexually exploited were searched, along with recent articles on the Guardian Group website.

\section{Defining the problem}

The sexual exploitation of children can take many forms including: trafficking, prostitution, sex tourism, mail-order-bride trade, involvement in pornography, stripping, battering, incest, rape and sexual harassment (Estes, 2001). Each of these requires a context-relevant solution (May-Chahal \& Herczog, 2003). This paper focuses specifically on the commercial sexual exploitation (CSE) of children and young people as far as possible, although the distinction between CSE and other forms of abuse is not always clearly defined.

The term 'child' is used as defined by the 1989 United Nations Convention on the Rights of the Child, Article 1 as "every human being below the age of 18 years unless, under the law applicable to the child, majority is attained earlier". While adhering to the focus on under 18 year-olds, we refer to both 'children' and 'young people'. This is important for two reasons: firstly young people in their teenage years do not consider themselves as 'children'; and secondly age differentiation is clearly defined for the first time within the Sexual Offences Act (Home Office, 2003), with different penalties given to 'abusers' of children according to the age of the 'child'.

The sexual abuse of children involves practices by which a person, usually an adult, achieves sexual gratification, financial gain or advancement through the abuse or exploitation of a child's sexuality by abrogating that child's human right to dignity, equality, autonomy, and physical and mental well-being (Estes, 2001). Trafficking became enshrined in international law for the first time in 2002, in the Palermo Protocol, which defines it as the recruitment, transportation, harbouring or receipt of a person for the purposes of exploitation, whether sexual or otherwise. 
The term commercial sexual exploitation (henceforth CSE) is distinguished from sexual abuse per se, by focusing on the use of children for some form of 'pecuniary advantage', understood in the wider sense to include cash and rewards in kind so long as there is some means of accounting in monetary terms. The Declaration and Agenda for Action of the World Congress Against Commercial Sexual Exploitation of Children held in Stockholm in 1996 provided this definition of the practice in general:

'The commercial sexual exploitation of children is a fundamental violation of children's rights. It comprises sexual abuse by the adult and remuneration in cash or kind to the child or a third person or persons. The child is treated as a sexual object and as a commercial object. The commercial sexual exploitation of children constitutes a form of coercion and violence against children, and amounts to forced labour and a contemporary form of slavery'.

In the rest of this paper, we review the literature on the three main forms of commercial sexual exploitation (through prostitution, pornography and trafficking) and then consider information about ways of protecting children and young people from such abuse.

\section{Abuse through prostitution}

Child prostitution refers to "the sexual exploitation of a child for the remuneration in cash or in kind, usually but not always organised by an intermediary (parent, family member, procurer, teacher etc" (Estes, 2001). The exchange is exploitative because it comes about in a relationship of unequal economic, cognitive, and psycho-social power.

In recent years, the term ' child prostitute' and similar terms have been replaced in the UK and elsewhere by others such as 'children abused' or 'children exploited' through prostitution (Barnardos 1998; 2002 Spangenberg, 2001), reflecting a paradigm shift from a 'punishment' to a ' welfare' model ( Barrett and Melrose, 2003). This approach recognises the need to focus on more effective prosecution of coercers (the pimps) and the offenders or abusers (those paying to have sex with children (Home Office/ Department of Health, 2001; Barnardos, 2002).

Quantifying the scale of prostitution involving children and young people is problematic since much activity is hidden away in brothels, massage parlours and saunas, and there are clear practical constraints and ethical issues in conducting appropriate research (Melrose, 2002; Melrose et al., 2002). Available Home Office data are of limited use in estimating numbers involved in prostitution, and offences concerning child abuse do not currently distinguish those where commercial sexual exploitation is a factor. The Crime and Disorder Act (1998) sought to end the practice of cautioning or convicting a female under the age of 18 for prostitution and while this move must be applauded, as a result in 2001 there were only 8 cautions ('offence by prostitution') reported against young women between the ages of 15 to 18 years. (National Statistics, 2002).

Estimates of the numbers of young people involved in prostitution in the UK range from around 2000 a year with one third under 16 years (Bluett et al., 2000), to up to 5,000 (Barrett, 1998). In a study conducted by Barnardo's, 48 agencies combined knew of over 600 girls and young women and 150 boys and young men 18 years and younger who were involved in prostitution (McNeish, 1998). A 2001 review of the government guidance on Safeguarding Children (Swann \& Balding) found that over three quarters of all Area Child Protection Committees in England reported some children involved in prostitution in their area. 
What is known is that abuse through prostitution affects children and young people of different ages, both male and female, and encompasses a range of exploitative behaviours, many of which combine extreme and degrading forms of physical, emotional and sexual abuse (Barnardo's, 1998; Barnardo's, 2002). Furthermore, recent years, have witnessed a decrease in the age at which children and young people are first exploited through prostitution (Spangenberg, 2001; Palmer, 2001), with girls as young as nine and boys as young as six known to have been abused in this way (Barnardo's, 2002).

Although by no means a homogenous group, a number of studies have highlighted similar patterns of disadvantage for children and young people exploited through prostituion. These include factors such as: family problems; abuse and/or violence; running away from home or from substitute care; truanting from school; peer pressure; drugs; sleeping rough and losing contact with family and social networks. (Melrose et al. 1999; Pearce 2000; Department of Health el al. 2000; Stein and Wade, 2000; Valios, 2001; Taylor-Browne et al., 2002; Phoenix, 2002; Cusick et al., 2003; Pearce, 2003; Scottish Executive, 2003).

Yet these are clearly not the only predisposing factors. Young people may engage in prostitution whilst living at home or in local authority care. Barnardo's claim that more than one third of young people seen since 1995 by their services lived at home with their parents ${ }^{1}$, and experience of residential care has been linked with vulnerability to exploitation through prostitution for boys as well as girls (Matthews, 2000).

Other reasons for entry into and continuing in prostitution are less tangible, and relate to issues of basic needs such as food and accommodation (Phoenix, 2002; Pearce, 2003), or because young people want things that they cannot afford through other means which leads in some cases to their own decision to become involved in prostitution (Melrose et al., 1999). There are also clear indications that, once involved, some young people experience a particular lifestyle that affords them things that they could not otherwise have (Taylor-Browne et al., 2002)

While there are many similarities in the patterns of disadvantage that make both girls and boys vulnerable to abuse through prostitution, for boys these other factors can coincide with further rejection or alienation, resulting from them disclosing to a parent or carer that they are gay (Palmer, 2001; Barnardo's, 2002). Palmer (2001) describes two main, but not exclusive, categories of boys and young men who get drawn into prostitution: those 'escaping' from a situation which leaves them vulnerable to abuse, who generally end up on the street entering transactional sex for survival; and those who are 'conditioned', sometimes in early childhood, into abusive activity which eventually leads them into a life of prostitution and later to possible pimping and abuse of other vulnerable young people.

Overall, boys and young men selling sex are thought to be far less visible than girls and young women, probably resulting from the additional stigma of homosexuality and of men selling sex. Sexual exchanges happen in less open places where they are less likely to be identified, such as public toilets, parks, bus and train stations, cruising areas and multi-purpose shopping areas and arcades. Mobile phones and the Internet provide further covert ways of making contact and enabling activity to remain hidden (Donovan, 1991). Little is known about the profile of those buying sex from boys and young men, but anecdotally most are said to be heterosexual married 
men, bisexual men or those not confident to be openly homosexual (McKegany and Bloor, 1990)

In recent years, much more has come to be understood about the complexities and dynamics surrounding the prostitution of girls and young women. Pearce (2003) identified three categories of girls and young women exploited through prostitution: those who were at risk of being exploited through the types of lifestyles and relationships that they were involved in; those who swapped sex for favours such as shelter, food, things they felt they needed or wanted; and those who defined themselves as prostitutes. A study by Barnardo's (1998) identified four stages of taking and maintaining control of the lives of girls and young women. The first stage involves ensnaring a young person through providing gifts and an expensive lifestyle; the next stage is about creating dependency and encouraging cutting of ties with family and friends; the third stage involves taking control over all aspects of the young girl's life; and finally total dominance occurs with the creation of a 'willing victim' prepared to do anything including having sex with other men in order to please the 'boyfriend'. Further research has identified the particular vulnerabilities of girls and young women to exploitation through 'pimping' and the consequent emotional and physical abuse from such coercive relationships (May et al., 2000)

Research also highlights the complex inter-relationship between drug use and sexual exploitation (Cusick et al., 2003). This works either through coercers preying on a young person's drug dependency and entrapping them through managing their supply of drugs in return for payment through prostitution; or by generating a dependency on highly addictive drugs as a means to subsequently control their lives and their involvement in prostitution (Pearce, 1999; May et al., 2000; Somerset, 2001; Barnardo's, 2002; Thompson, 2003). There is increasing evidence of widespread use of crack cocaine among women involved in sex work (Ward et al., 2000), and evidence that young people involved in prostitution report higher levels of drug use than other young people (Cusick et al., 2003). Moreover drug dependency has been identified as a major obstacle to enabling a choice to exit from prostitution (Cusick et al., 2003). There does appear however to be a broader relationship between drug use and vulnerability more broadly and not just affecting those exploited through prostitution. Other research has drawn a link between significantly higher levels of drug use among young people who sleep rough, are persistent offenders, who run away on a serial basis and who are not attending school or are excluded from school (Goulden and Sondhi, 2001).

\section{Abuse through pornography}

Child pornography is defined as "any representation of a child engaged in real or simulated explicit sexual activities or any representation of the sexual parts of a child for primarily sexual purposes" (Optional Protocol to the Convention on the Rights of the Child, 2002).

In recent years, the Internet and related technology such as mobile phones have come to provide both important ways for potential offenders to access children and young people, and quick and effective mechanisms for the sale and transfer of pornographic images. While such activity existed long before the existence of the Internet, new technology has added a 'virtual' variable to the problem of the sexual abuse of children, particularly in relation to pornography and paedophilia. At the same time, it has removed the communication constraints and social sanctions previously surrounding pornography and paedophilia (Arnaldo, 2001). At the touch of button, child abusers can access thousands of exploitative and even live images (Downey, 2002a; Hill, 2003). 
There is, however, limited systematic and reliable data currently available on the problem of child pornography and the Internet, its impact on children or the relationship between child abuse and child pornography (Renold et al., 2003).

During 2000, there were a total of 81 convictions of 'possessing obscene material for gain' under the Obscene Publications Act (1959); 218 convictions of 'taking or making indecent photographs or pseudo-photographs of children' under the Protection of Children Act (1978); and 77 convictions of 'possessing an indecent photograph or pseudo-photograph of a child' under the Criminal Justice and Public Order Act (1988) (Home Office, 2002b).

Although images depicting the abuse of children can have considerable commercial value (Wyre, 2003), they are often traded or exchanged between paedophiles rather than sold (Estes, 2001), the most recent world wide mechanism being through "peer to peer' transfer (Gillen, 2003a). Although there is no direct financial gain in these transactions, they bolster the demand for pornography and indirectly perpetuate and extend the abuse of children for these purposes. Recent high-profile police investigations, such as Operation Ore, have seen the arrests of hundreds of people on charges of possessing child pornography, downloading and making pornography on the Internet. The magnitude of the operation was thought to be beyond the current capacity of the police force (BBC News Online, 2003).

The Internet has also become a significant mechanism for 'grooming' children for sexual exploitation. Grooming is defined as: 'a course of conduct enacted by a suspected paedophile, which would give a reasonable person cause for concern that any meeting with a child arising from the conduct would be for unlawful purposes' (Home Office, 2002a). There has been increasing concern and media coverage of the role of the Internet in enticing children into sexual activity with paedophiles and prostitution as well as its use to traffic and sell children (Barnardos, 2002).

One study conducted over five years in chat rooms intended for children and teenagers highlighted how communication technologies, including mobile phones, are used for exploitation and abuse and how they limit attempts to supervise the children's use of the Internet (O'Connell, 2003). The term 'cybersexploitation' is coined by the author to cover the process of 'grooming' children in cyberspace with the intention to sexually abuse a child in the real world. This same study provides indepth insight into how the grooming process works, including how victims are selected; how paedophiles collaborate together to identify children that meet desirability criteria, and patterns of grooming conversations from relationship-building through to engaging the child in sexual fantasy enactment, which tend to involve coercion, control and aggression.

The Internet has provided therefore scope for forms of sexual abuse of children that present serious challenges for traditional policing methods and community safety strategies. (Kennison \& Read, 2003). Furthermore, it has created new larger social networks with fewer controls. Virtual cyberspace allows paedophiles, previously socially marginalized, to communicate freely with each other, thereby endorsing and validating behaviours that are exploitative of children. The Internet allows them to subvert their identities and to assume fictitious names, ages, descriptions and intentions in order to lure children. Furthermore, chat rooms provide a safe haven for collecting child pornography, exchanging pictures, images and video footage. Above all, they facilitate more direct contact with children through the use of direct email or mobile phones. 
However, the potential links between the possession of child pornography or the taking of indecent photographs of children and actual abuse are rarely acknowledged, or are played down. Edwards (2000) demonstrated how in both magistrates and Crown courts, a clear distinction is made between the taking of pornographic photographs of children and the abuse of children. Defendants charged with possession or distribution of child pornography were said to successfully minimise their actions in the eyes of the court, while judges failed to recognise the danger posed by defendants convicted of possession and distribution. This was reflected in the very short prison sentences often given to those found guilty.

\section{Abuse through trafficking}

Trafficking is defined the Palermo Protocol within the United Nations Protocol to Prevent, Suppress, and Punish Trafficking in Persons. Although the Protocol deals with both adults and children, it makes specific reference to the situation of children.

There is clearly an overlap in the UK between A recent review of information on trafficking of children and young people to and through the UK (Candappa, 2003) provides a comprehensive account of some of the complex issues involved, and highlights the overlap between trafficking of children and young people and their sexual exploitation. This review found that trafficking generally takes place in two major ways: cross-border international trafficking, and internal trafficking within the borders of a country or state. There is evidence of young people being trafficked into the UK (brought under false pretences of a better life and opportunities) and subjected to exploitation by pimps to work either on the streets or hidden away in brothels or massage parlours (Kelly and Regan, 2000; Arie, 2003).

Certain factors are known to foster international trafficking of people generally. These include: globalization of transport, markets and labour; women's socio-economic inequality; economic transition (especially in the Former Soviet Union), social dislocation as a result of conflict; and demand factors (Candappa, 2003). Pearce (2000) outlines how economic and political changes that have taken place in both central and eastern Europe, and within Western European economies, have brought specific forms of 'feminised poverty; and have seen the increasing movement of impoverished children within and between European countries. Added to these are increasingly restrictive migration and refugee and asylum politics in the countries to which children and women are trafficked (Walthius and Blaak, 2002), which make the trafficking of humans across borders a lucrative business.

Research on international trafficking is still very limited and is restricted to mapping of the problem, reviews of frameworks and policy responses. Even in relation to the trafficking of adults, data on the numbers involved in trafficking, either as victims or perpetrators, are very unclear and largely guesstimates (International Organisation on Migration 2001; Kelly, 2002). Furthermore, figures for women and children are usually combined, although Kelly (2000) has estimated that $10-30 \%$ of those trafficked are minors. The US Department of State (2002) estimates that, globally, 700,000 women and children are trafficked per year. However, as a rule, different studies do not cross-reference or complement each other to provide a solid research base (Kelly and Regan, 2002).

At least 250 children are thought to have been trafficked to the UK in the last five years (UNICEF, 2003). However, this figure is thought to largely underestimate the actual number of trafficked children, most notably because of the relative newness of trafficking as a phenomenon and the fact that many local authorities are only just beginning to keep records of trafficking incidences. 
Many children arrive in the UK accompanied by an adult for legitimate reasons such as education, re-unification with family or fleeing war or other conflict situations. In the majority of cases, the adult with the child is allowed to enter the UK. If, however, there are concerns about the child or the relationship between adult and child, then various steps are taken to protect the child, including taking the child into social services' care or returning the child to their family in the country of origin.

Most of the limited information on child trafficking in the UK relates to children who are unaccompanied, and who come to the attention of the authorities at the point of claiming asylum. Although there are useful descriptive accounts of young asylum seekers and their vulnerability to exploitation (UNICEF, 2003; Kelly, 2002), there is very little concrete data on the scale of the problem. The lack of clear identification of people who are trafficked means that they are often classified as ' undocumented', 'illegal immigrants', or, if trafficked for the purposes of prostitution, as 'prostitutes' and subjected to either deportation or detention in an immigration facility.

It is thought that unaccompanied children and young people who have not been trafficked but who are seeking asylum may be particularly vulnerable to exploitation once they arrive in the UK, especially when their immigration status is uncertain and they are not sure of their situation. At that point they have no money, they are often placed in hostel-type accommodation where they are highly vulnerable and easily targeted for exploitation, yet are cut off from appropriate support. This is particularly the case when they are housed away from the local authority with responsibility for them.

Other children are brought into the country for the purpose of exploitation. Children from Africa tend to disappear from social services care, while a trafficker or third party usually meets those from Eastern Europe at the point of entry. Others enter clandestinely in the backs of lorries, some who are older arrive with a student visa, others arrive with a man claiming to be a boyfriend, and the age of the girl or young woman is disguised. Once in the UK, they may be used in prostitution or domestic exploitation, or they are trafficked through the UK to other European countries. Children and young people entering the country via these routes only usually come to the attention of authorities after they have been exploited.

Once in the UK, young people are moved around to service demand in various parts of the country, although the picture of how and to where they are trafficked is actually very unclear and it is often only single cases that come to light in such diverse places as West Sussex, Newcastle and Glasgow (UNICEF, 2003). There does appear to be some diversification of trafficking routes within the UK to areas where authorities are less vigilant or less equipped to deal with the issue. Young people who arrive in the UK under false documentation organised through pimps have no rights to remain if they manage to escape from their situations or when the industry has no further use for them. Seeking help will most often lead to deportation.

There currently appears to be little evidence of trafficking of boys for the purposes of sexual exploitation (Kelly, 2002). Various strategies are used to recruit women, including young women, in their home countries. These include deception, promises of a better life and exploitation of the lack of opportunity and life chances available to them at home. Reportedly, those coming from West Africa are bound by 'curses' which they believe can only be lifted once the cost of their passage to the UK has been repaid (Downey, 2002b). Once recruited, various mechanisms are used to control and keep young women working including rape, assault, drugs, threats of harm to family members, and removal of identity documents. Although some women 
know they are being recruited for 'escort work', they are still deceived in terms of conditions of their employment and ability to pay off traffickers (Candappa, 2003)

\section{Mechanisms for protection: legislative and policy frameworks}

Legislation and protocols, both international and national, offer one route to protecting children and young people from commercial sexual exploitation. The First World Congress on the Commercial Sexual Exploitation of Children, held in Stockholm in 1996, for the first time recognised commercial sexual exploitation as a human rights, labour, health, education and law enforcement problem. A second World Congress, held in Japan in December 2001, reviewed progress that had been made in the intervening five years. This included the European Council Framework Decision on Combating Trafficking in Human Beings and Combating the Sexual Exploitation of Children and Child Pornography (2000), and the Council of Europe's Convention on Cybercrime (2001). In 2002, an optional protocol was added to the United Nations Convention on the Rights of the Child arguing against 'the sale of children, child prostitution and child pornography. Further details of international frameworks to protect children against CSE can be found in Chase and Statham (2004).

In the UK, the legal and policy initiatives that aim to protect children and young people from commercial sexual exploitation were described earlier in the introduction to this paper. Reforms proposed under the Sexual Offences Bill, which became law in May 2004, have mostly been warmly welcomed by many organisations concerned with the safety and protection of children (Leason, 2002), despite some concerns that they do not go far enough to protect the most vulnerable children from exploitation particularly with respect to trafficking (UNICEF, 2003).

\section{Approaches to support}

There is some disagreement about the approach to support that should be fostered by legislative and policy frameworks. International lobby groups such as the 'antiviolence' lobby tend to view prostitution as a form of sexual violence, while pro-rights groups advocate for the right to work as a prostitute under non-discriminatory or decriminalised systems (Scrambler and Scrambler, 1997; International Prostitutes Collective, 1999) However, Pearce (2000) points out that both sides are unified in their view of the need for greater protection of children (Scrambler and Scrambler, 1997; Barrett, 2000).

While child protection procedures currently provide the framework in the UK for protecting children and young people from all forms of abuse and exploitation, their relevance and adequacy in protecting and supporting children in relation to commercial sexual exploitation has been questioned (Green 2000; Calder 2001). Some authors highlight the inadequacies of inter-agency child protection systems to adequately address abuse through prostitution or other forms of perceived exploitation (Ayre and Barrett, 2000).

Others have more fundamental criticisms of this approach. (Phoenix, 2002) questions the relevance of 'simply transposing the problem of youth prostitution into a problem of child (sexual) abuse' and claims that this ignores the complexities surrounding 'youth prostitution'. Phoenix argues that a distinction is often made between those 'deserving' of protection and support because they accept the services and support offered, and those who continue to be involved despite being offered support to stop their involvement in prostitution. In a similar vein, Barrett and Melrose (2003) point out the anomalies of government guidance stating that children exploited through 
prostitution should be defined as ' children in need' (Department of Health/ Home Office, 2001) unless they 'persistently' and 'voluntarily' return to prostitution, in which case they should be processed through the criminal justice system.

Aside from the political debate about the relative merits of different approaches to protecting young people, there is also a highly practical debate in that young people involved in prostitution in many cases will not perceive themselves as being victims of abuse (Barnardo's, 1998), nor will they define themselves as 'child prostitutes' since they view the term degrading, labelling and stigmatising (Calder, 2001). Furthermore, there are questions as to whether current child protection systems have the capacity to adequately address the issues of abuse through prostitution (Green, 2000; Barrett and Melrose, 2003)

\section{Intervention strategies}

Legislative and policy reforms alone, do not provide adequate protection for children and young people. Pearce (2000) points to the example of the Netherland where highly pragmatic and far reaching reforms including the removal of a ban on brothels; brothel inspections to ensure that minors are not employed; a new section 250a of the criminal code creating an offence for forms of commercial operation of involuntary prostitution and prostitution involving minors; and the abolishment of the 'complaint requirement' for sexual acts involving children between 12 and 16, meaning that a prosecution can be made without a child making a statement; could not ensure the safety of young people. In addition, extensive training and awareness-raising across a range of agencies is required in order to set up multi-agency protocols, and to alert professionals to key warning signs that a young person is vulnerable abuse exploitation (Valios, 2001; Swann and Balding, 2001). We review below the literature on strategies to support children and young people at risk of, or exploited through, prostitution, pornography and trafficking. It is important to note, however, that there are few studies to date that have evaluated the outcomes of different interventions. Most reports are descriptive accounts of the types of services that are provided and the types of young people that they support.

\section{Exploitation through prostitution}

A number of studies highlight the complex difficulties faced by young people trying to exit prostitution, including financial difficulties and debt; drug dependency; single parenthood; lack of qualifications and training to enable them to look for alternative employment; housing problems; criminal convictions (through prostitution); and abusive partners and/or pimps. (Taylor-Browne et al., 2002). The longer young people remained involved, the more entrenched became the patterns of behaviour that kept them exploited, making it difficult for them to find a way out, particularly when they had lost contact with family and friends and their most direct peer groups were also all involved in prostitution (Taylor-Browne et al., 2002; Palmer, 2001) or they have an on-going drug dependency (Cusick et al, 2003).

Other studies highlight the difficulties for agencies in supporting young people involved in prostitution, including denial by young people; drug use and dependency; and the difficulty of balancing choices and rights with effective protection (see, for example, Swann \& Balding, 2001). Young people may have developed a fear and mistrust of existing services based on previous experiences (Cusick, 2002; Pearce, 2003). Services which provide local outreach and drop-in support, so called 'recovery' services (Department of Health et al., 2000), and those that adopt a strong multi-agency approach, appear to be the most effective in both protecting young people from exploitation and collecting evidence to be used against abusers (May et 
al., 2000). Unfortunately, however, these types of intervention are rare and there is still a general lack of protection offered by the criminal justice system when reporting pimps for violence and abuse (May et al., 2000)

There is an increasing recognition of core principles that underpin seemingly successful strategies to support children and young people. Holistic, nonjudgemental and multi-dimensional support services are required which are able to address the complex needs of young people and are based largely on harm minimisation approaches rather than on 'quick fixes'. Services need to address immediate needs such as homelessness, drug and alcohol dependence and single parenthood, while at the same time promoting young people's central participation in initiatives to support them, and focusing on raising their self esteem and ability to control their lives (Barnardo's, 2002; Miller, 2003).

However, support for young people at risk remains geographically patchy across the UK, with the majority of services concentrated in major cities. Despite multi-agency policies and protocols in place, many voluntary agencies face difficulties in joint working, including problems in agreeing definitions of risk and confidentiality (Phoenix, 2003).

\section{Exploitation through pornography}

Various strategies have been explored in recent years to combat the proliferation of child pornography through the Internet, with variable success. Such strategies include: legal and regulatory approaches imposed by governments; policies of selfregulation adopted by the Internet industry; and action by individuals, parents, civic groups and NGOs - or a combination of all of these. In 2000, the Children's Charities Coalition on Internet Safety (CHIS) was launched. The coalition campaigns to raise awareness of the hazards children may encounter when using the Internet; to get companies in the Internet supply chain to adopt child safety policies; and to lobby Government for action - including changes in the law if necessary.

Identifying and providing support to children and young people exploited through pornography is highly complex and in some cases impossible (Downey, 2002a; Gillen, 2003a). Furthermore, although social workers receive high quality training in child protection, they are often unaware of the dangers posed by the Internet (Downey, 2002a).

\section{Exploitation through trafficking}

Children arriving in the UK alone are entitled to protection under the Children Act, although there is evidence that generally this provision is insufficient to protect and support children and young people (Refugee Council, 2003). For complex reasons, including experiences of abuse and rape, threats to family back home and other controlling mechanisms such as curses and 'voodoo', children taken into care who have been trafficked often flee to meet their trafficker, or they are abducted. The accommodation provided by social services is normally inadequate to provide protection and support, since victims of trafficking require 'round the clock' supervision and highly specialised support and counselling to enable them to escape from their traffickers (Downey, 2002b). On the whole, social services departments lack knowledge about the complexities of trafficking and how to identify and investigate it (Gillen, 2003b; Somerset 2001), although there are some examples of authorities developing procedures for responding to the needs of vulnerable young people arriving from abroad who might be 'at risk' from exploitation (Kent Social Services Department, 2002; Kent County Council, 2002). 
The organisation ECPAT (End Child Prostitution, Pornography, Trafficking) with AntiSlavery International have highlighted steps that need to be taken to effectively combat trafficking in the UK and provide adequate support. These include the provision of safety and extended leave to remain for those trafficked, in line with article 6 of the UN Protocol on Trafficking and clearer protocols between social services and immigration (ECPAT, 2001). A Counter-Trafficking Steering Group, initiated by the National Missing Persons Helpline, was set up in 2002 involving police, immigration, the Home Office, voluntary organisations and social services. In addition, the Home Office has designed a web-based toolkit on trafficking, to raise the profile and understanding of the issues at a local authority level (Home Office 2003).

\section{Conclusions}

This review has attempted to draw together what is known about three important areas of commercial sexual exploitation of children and young people: exploitation through prostitution: through pornography and related activity; and through trafficking for the purposes of exploitation. It has highlighted the strengths of the existing research base as well as identified gaps in knowledge in these areas.

There is a need for greater exploration and research around a number of areas of exploitation of children. For example, more needs to be known about young asylum seekers, their vulnerability to abuse through prostitution and the effectiveness of current support mechanisms. The relationship between use of the Internet and other forms of abuse against children and young people, including grooming for prostitution, needs more attention. There is a general need for clearer and more systematic data collection on all areas of abuse, particularly in the light of the changes introduced by the Sexual Offences Act (2004).

More broadly, further work is necessary in terms of capacity building, training and awareness-raising for a range of professionals, including immigration officers, social workers, the police and other professionals providing direct support to children and young people at risk of exploitation. Finally, there is clearly a debate still to be had around the appropriateness and adequacy of existing child protection procedures to address these types of commercial sexual exploitation of children and young people.

\section{Acknowledgement}

This review was undertaken by the Thomas Coram Research Unit for the Children's Safeguards Unit at the Department for Education and Skills. The views expressed in this article are those of the authors and are not necessarily those of the Department. 


\section{References}

Arie, S.(2003) Janie's Story. The Guardian, 5 November.

Arnaldo, C.A. (Ed) (2001) Child Abuse on the Internet: Ending the Silence. Paris, UNESCO

Ayre, P. \& Barrett, D. (2000). 'Young people and Prostitution: an end to the beginning'. Children and Society, 14, 48-59.

Barnardo's (1998) Whose Daughter Next? Children abused through prostitution. Barkingside, Barnardo's.

Barnado's (2002) Stolen Childhood: Barnardo's work with children abused through prostitution. Barkingside, Barnado's.

Barrett, D. (1998) 'Young people and prostitution: perpetrators in our midst'. International Review of Law, Computers and Technology, 12, 3, 475-86

Barrett, D (ed.) with Barrett, E. \& Mullenger, N. (2000) Youth Prostitution in the New Europe: the growth in sex work, Lyme Regis. Russell House Publishing.

Barrett, D., and Melrose, M (2003).Courting Controversy- children sexually abused through prostitution- are they everybody's distant relative but nobody's children? Child and Family Law Quarterly, 15, 4.

Bluett, M., Walker, A., Goodman, J. and Adeyemo, J. (2000) Somewhere Safe: accommodation needs of children and young people at risk on the street.

Calder, M (2001) 'Child Prostitution: Developing Effective Protocols'. Child Care in Practice. 7, 2, 98-115

Candappa, M (2003). Scoping Exercise on Trafficking of Children and Young People To and Through the UK. Report to the Save the Children UK (unpublished)

Chase, E. and Statham, J. (2004) The Commercial Sexual Exploitation of Children and Young People: an overview of key literature and data. www.acpc.gov.uk/publications_cons.htm [6 May 2004]

Cusick, L. (2002) 'Youth Prostitution: a literature review'. Child Abuse Review 11, 4, 230-251

Cusick, L., Martin, A. and May, T. (2003). A Study of Young People, Vulnerability and Involvement in Drug Use and Sex Work. London, Home Office.

Department of Health, Home Office, Department for Education and Employment (1999) Working Together to Safeguard Children: A guide to inter-agency working to safeguard and promote the welfare of children. London, The Stationery Office.

Department of Health, Home Office, Department for Education and Employment, National Assembly of Wales (2000). Safeguarding Children Involved in Prostitution: Supplementary Guidance to Working Together to Safeguard Children. London, The Stationery Office. 
Department of Health/ Home Office (2001). National Plan for Safeguarding Children from Commercial Exploitation. London, The Stationery Office.

Donovan, K. (1991) Hidden from View. An Explanation of the Little-known World of Young Male Prostitutes in Great Britain and Europe. Home Office and West Midlands Police.

Downey, R. (2002a) 'Victims of wonderland'. Community Care, 1412, 30-31.

Downey, R. (2002b) ‘Trade in misery’. Community Care, 1407, 28-30

ECPAT (2001) Recommendations from Trafficking of People into the UK. Meeting organised by the Anti-Slavery International and ECPAT UK. 3 December 2001.

http://www.antislavery.org/archive/other/trafficking-recommendations-UK-2001.htm. accessed 15.11 .04

Edwards, S. (2000) 'Prosecuting child pornography: possession and taking of indecent photographs of children'. Journal of Social Welfare \& Family Law, 22, 1, 121.

Estes, R. J. (2001) The Sexual Exploitation of Children: A working Guide to the Empirical Literature. University of Pennsylvania, School of Social Work. Philadelphia. PA.

Gillen, A. (2003a) Race to Save New Victims of Child Porn. The Guardian, 4 November.

Gillen, S. (2003b). Safe houses win support in battle to keep pace with child traffickers. Community Care 1484,16 -17.

Goulden, C. and Sondhi, A. (2001) At the Margins: Drug use by vulnerable young people in the 1998/99 Youth Lifestyles Survey. Home Office Research Study 228. London, Home Office Research, Development and Statistics Directorate.

Green, L. (2000). Shift in strategy may leave issue on the margins. Community Care, 1324, 8-9.

HM Treasury (2003) Every Child Matters. Government Green Paper. London, The Stationery Office.

Hill, A. (2003) Child abuse shown live on Internet. The Observer, 9 November.

Home Office/ Department of Health (2001) National Plan for Safeguarding Children from Commercial Sexual Exploitation. London, Department of Health.

Home Office (2002a) Protecting the Public: Strengthening protection against sex offenders and reforming the law on sexual offences. London, Home Office.

Home Office (2002b). Commons Hansard, 380, 1000 (12 Feb). (Table showing the number of defendants convicted at all courts for offences relating to child pornography, England and Wales, 2000)

Home Office (2004) The Sexual Offences Act. London, The Stationary Office. 
Home Office (2003) Crime Reduction Tool Kits: Trafficking People. Available at www.crimereduction.gov.uk/toolkits .accessed 15.11 .04

International Organisation on Migration (IOM) (2001) Victims of Trafficking in the Balkans: A Study of Trafficking in Women and Children for sexual exploitation to, through and from the Balkan Region, Geneva.

International Prostitutes Collective (2000) Some Mother's Daughter: the hidden movement of prostitute women against violence, London: Crossroads Books.

Kelly, L. (2002) 'Journeys of Jeopardy: A review of research on trafficking in women and children in Europe'. Geneva, IOM Migration Research Series, No.11.

Kelly, L. \& Regan, L. (2000) 'Stopping Traffick: Exploring the extent of, and responses to, trafficking in women for sexual exploitation in the UK'. Policy Research Series Paper 125, London, Home Office.

Kennison, P. \& Read, M. (2003) The Internet and Child Protection (Part 1). Community Safety Journal, 2, 2, 20-25

Kent Social Services Department (2002) Interagency Protocol: Vulnerable children and young people arriving from abroad. (unpublished)

Kent County Council (2002): At risk profile (unpublished)

Leason, K. (2002). 'Charities welcome proposed sex offences to curb exploitation'. Community Care, 1450,18-19.

Matthews, P. (2000) A Review and a Way Forward: A Report on the Sexual Exploitation of Boys and Young Men. Barkingside, Barnardo's.

May, T., Haracopos, A. and Hough, M. (2000) For Love of Money: Pimps and the Management of Sex Work. London, Home Office.

May-Chahal C. and Herczog, M. (2003) Child sexual abuse in Europe. Strasbourg, Council of Europe.

McKegany, N. \& Bloor, M. (1990) 'A Risky Business', Community Care, 5 July.

McNeish, D. (1998). An overview of agency views and service provision for young people abused through prostitution. 31-46 In Whose Daughter Next?: Children abused through prostitution. Barkingside, Barnardo's.

Melrose, M., Barnett, D. and Brodie, I. (1999) One Way Street? Retrospectives on childhood prostitution. London, The Children's Society and University of London.

Melrose, M. (2002) 'Labour Pains: Some considerations of the difficulties of researching juvenile prostitution'. International Journal of Research Methodology, Theory and Practice, 5, 4, 333-351

Melrose, M., Greenwood, H. and Barrett, D. (2002) Young people abused through prostitution. Highlight No. 194. London, National Children's Bureau

Miller, A. (2003). 'Facing down exploitation'. Community Care, 1460, 32-33 
National Statistics (2002) Criminal Statistics, England \& Wales for 2001: Supplementary Tables. London.

http://www.homeoffice.gov.uk/rds/pdfs2/crimstat01vol1.pdf [6 May 2004]

http://www.homeoffice.gov.uk/rds/pdfs2/crimstat01vol2.pdf [6 May 2004]

http://www.homeoffice.gov.uk/rds/pdfs2/crimstat01vol3.pdf [6 May 2004]

O'Connell, R. (2003) A Typology of Child Cybersexploitation and Online Grooming Practices. University of Central Lancashire. Preston.

Palmer, T. (2001) No son of mine! Children abused through prostitution. Barkingside: Barnardo's

Pearce, J.J. (1999) 'Selling sex, doing drugs and keeping safe' pp118-127 in A. Marlow and G. Pearson (Eds) Young People, Drugs and Community Safety. Lyme Regis, Russell House Publications

Pearce, J. (2000) 'Young People and Sexual Exploitation: a European Issue'. Social Work in Europe, 7, 3, 24-30

Pearce, J. (2003) It's someone taking a part of you: a study of young women and sexual exploitation. London, National Children's Bureau.

Phoenix, J. (2002) 'In the name of protection: youth prostitution policy reforms in England and Wales'. Critical Social Policy 22, 2, 353-375.

Phoenix, J. (2003) Working with Youth Prostitution: a database: www.regard.ac.uk/research_findings/R000223916/report.pdf [6 May 2004]

Renold, E., Creighton, S., with Atkinson, C.,\& Carr, J. (2003). Images of Abuse: a review of the evidence on child pornography. London, NSPCC.

Refugee Council (2003) Support arrangements for 16 to 17 year old unaccompanied asylum seeking children. London, Refugee Council.

Scottish Executive (2003) Young Runaways and Children Abused Through Prostitution. Edinburgh, Scottish Executive.

Scrambler, G.\& Scrambler, A. (1997) Rethinking Prostitution: Purchasing Sex in the 1990's, London: Routledge

Somerset, C. (2001) What the Professionals Know: the trafficking of children into, and through the UK for sexual purposes. London, ECPAT UK.

Spangenberg, M. (2001) Prostituted Youth in New York City: An Overview. New York, ECPAT USA.

Stein, M. \& Wade, J. (2000) Helping care leavers: problems and strategic responses, London, Department of Health.

Swann, S. and Balding, V. (2001) Safeguarding Children Involved in Prostitution Guidance Review. London, Department of Health.

Taylor-Browne, J., Broadfoot, F., Broadhead, L., Downie, A., McKetty-Campbell, M. (2002) More than One Chance: Young people involved in prostitution speak out London, ECPAT UK. 
Thompson, T. (2003). Crack turns vice girls into slaves of sex. The Observer,12 October.

UNICEF UK (2003) Stop the traffic! End Child Exploitation. London, UNICEF.

United States Department of State (2002) Victims of Trafficking and Violence Protection Act 2000: Trafficking in Persons Report. Washington DC, Department of State.

Valios, N. (2001) ‘Falling prey to prostitution'. Community Care, 1371, 18-19.

Walthius, A. and Blaak, M. (Eds) (2002) Trafficking in Children for Sexual Purposes from Eastern Europe to Western Europe. Amsterdam, ECPAT Europe Law Enforcement Group.

Ward, H., Pallecaros, A., Green, A. and Day, S. (2000). 'Health issues associated with increasing use of 'crack' cocaine among female sex workers in London.' Sexually Transmitted Infections 76, 292-293.

Wyre, R. (2003) ‘No excuse for child porn'. Community Care, 1489, 38-40 